\title{
КРИОТЕРАПИЯ В КОМПЛЕКСНОМ ЛЕЧЕНИИ БОЛЬНЫХ С ВЕРТЕБРОГЕННЫМИ НЕВРОЛОГИЧЕСКИМИ СИНДРОМАМИ
}

\author{
А.В.Мусаев, Р.Г.Зейналов, С.Г. Гусейнова, С.С.Имамвердиева, Э.Э.Мустафаева, \\ А.Э. Рагимова, Л.Р.Нуриева, А.К.Шабанова, Э.Г.Исазаде \\ Азербайджанский НИИ Медищинской Реабилитащии
}

В последние годы среди новейших достижений современной физиотерапии большой интерес и распространение получил метод криотерапии (КТ). Криотерапия (kryos - холод; therapya - лечение (греч.)) - раздел физиотерапии, включающий физические методы лечения, отличительным признаком которых, является применение холода в качестве основного действующего физического фактора. Основу действия криотерапии на организм составляет быстрое снижение температуры тканей под влиянием холодового фактора в пределах криоустойчивости (5-10 ?C) без выраженных сдвигов терморегуляции организма $[3,4,11]$.

Согласно современным представлениям, в реализации эффектов КТ ведущая роль принадлежит нервной системе, обладающая высокой чувствительностью к криовоздействию. В частности, было установлено, что в коре мозга холодовая рецепция отображена значительно сильнее, чем тепловая. Влияние КТ на организм проявляется нейрорефлекторным действием, реализуемым посредством системы взаимосвязанных между собой реакций, в виде активации афферентных и эфферентных систем, выброса нейрогормонов, способствующих ускорению основных биохимических и метаболических процессов в тканях и клетках организма [3,7]. Исследования последних лет показали, что применение криотерапии сопровождается уменьшением болевого синдрома и воспалительного процесса, улучшает крово- и лимфообращение, нормализует капиллярный кровоток, возбудимость нейронов спинного мозга, способствует миорелаксации спазмированных мышц Важное значение отводится проти- воболевому действию КТ, которое объясняется "блокированием" болевых рецепторов и аксон-рефлексов, нормализацией возбудимости нейронов спинного мозга, а также уменьшением воспалительной реакции, и разрывом порочного круга "боль - мышечный спазм - боль". Последнее положение обуславливает широкое применение криотерапии при заболеваниях опорнодвигательного аппарата $[3,4,6,7]$.

В настоящее время существует множество видов криотерапии с использованием умеренно низких (от +20 до -30 ?С) и экстремально низких (-30?-180?) температур. В зависимости от площади, подвергаемой воздействию применяют общую и локальную криотерапию. При этом, особенностью реакции, на локальное криовоздействие является последовательное чередование процессов сужения, а затем расширения просвета кровеносных сосудов, наступаюшее через 1,5-2 часа после воздействия, что в свою очередь оказывает регулирующее действие на сосудистый тонус и способствует активации местного кровообращения, подавлению активности воспалительного процесса, стимуляции процессов регенерации и повышению общей резистентности организма $[7,11]$. Процессы, возникающие в подобном состоянии характеризуются также повышением проницаемости тканей, что представляется благоприятным фоном для последующего накожного воздействия лечебными факторами, способствующими повышению терапевтического эффекта криотерапии.

Таким образом, особенности в механизме действия криотерапии и ответной реакции на ее воздействия организма раскрывают широкие возможности для разработки 
новых эффективных методов криотерапии, сочетания ее с другими видами физических факторов, с учетом присущим им отличительных свойств, определением параметров воздействия, его интенсивности, временного интервала между воздействиями, а также от характера патологии. Одним из уникальных по своим целебным свойствам природных факторов Азербайджана, обладающим широким спектром физиологических и лечебных эффектов, является нафталанская нефть. Многочисленными исследованиями была доказана высокая эффективность применения нафталанотерапии в восстановительном лечении заболеваний периферической нервной системы $[6,9]$.

Среди заболеваний периферической нервной системы неврологические проявления остеохондроза позвоночника (НПОП) составляют до 70\%, возникая преимущественно в период активной трудовой деятельности и приводя к временной, а часто и стойкой потере трудоспособности $[2,5,10]$. Патологические изменения, возникающие вследствие остеохондроза позвоночника, способствуют возникновению отека, набухания и асептического воспаления соседних соединительнотканных и неврологических образований, что клинически проявляется различными клиническими синдромами. Рефлекторно возникающие изменения в спазмированной мышце, впоследствии, способствуют формированию в ней триггера, запускающего порочный круг поддержания боли, что способствует хронизации процесca, затрудняет лечение и существенно снижает качество жизни больных [2,5]. В связи с этим поиск новых эффективных методов лечения больных с НПОП является одной из актуальных проблем современной веретеброневрологии $[8,10]$.

Исходя из вышесказанного, целью настоящего исследования явилась разработка и клинико-патогенетическое обоснование методики применения криотерапии в комплексе с нафталанотерапией у больных с неврологическими проявлениями остеохондроза позвоночника (НПОП).

Исследование было проведено у 105 больных с НПОП позвоночника в возрасте 30-69 лет поступивших на восстановительное лечение. Рентгенологическое исследование и компьютерная томография, проведенные у больных, выявляли у них признаки дегенеративно-дистрофических изменений в поясничном отделе позвоночника, в виде снижения высоты межпозвоночного диска и сужения межпозвонковых щелей, наличия сколиоза, выпячиваний и грыж межпозвонковых дисков и др.

Наряду с общим клиническим и неврологическим обследованием у всех больных оценивали выраженность болевого синдрома с помощью визуальной аналоговой шкалы (ВАШ) и краткой версии опросника боли Мак-Гилл (MPQ). Качество жизни (КЖ) больных изучалось на основе Освестровского опросника "Нарушения жизнедеятельности при боли в нижней части спины" [1]. Для оценки состояния нервно-мышечного аппарата и объективизации результатов лечения проводилось электромиографическое (ЭМГ) и электронейромиорафическое (ЭНМГ) исследования. Электромиографическое исследование включало регистрацию биопотенциалов икроножной и передней большеберцовой мышц. ЭНМГ исследованием определяли скорость проведения импульсов (СПИ) по двигательным волокнам большеберцового и малоберцового нервов. Исследования проводились на 4-х канальном электронейромиографе фирмы Viking (N?COLET, CШA).

Оценка эффективности лечения проводилась на основе динамики клинических и электронейромиографических показателей по критериям "значительное улучшение", "улучшение" и "незначительное улучшение".

В зависимости от методики лечения больные были разделены на 2 группы. Первую группу больных составили 53 больных с НПОП, которые получали криотерапию в качестве монотерапии. Вторая группа 
больных (52 больных) получала криотерапию в комплексе с нафталанотерапией и массажем, которые проводились последовательно с интервалом в 2 часа.

Для проведения локальной воздушной криотерапии использовали современную установку "Kriojet Air Mini" (Германия), предназначенную для использования сухого охлажденного воздуха экстремальных температур. Струей холодного воздуха сначала воздействовали паравертебрально на поясничный отдел позвоночника в течение 5 минут, а затем на болевые точки, определяемые методом пальпации в течение 1-4 минут, в течение 10 дней. Нафталанотерапия проводилась в виде смазывания с укутыванием при температуре 37-38?, на сегментарный отдел позвоночника и пораженные конечности, в течение 15-20 минут, на курс 10 процедур.

При поступлении в стационар большинство больных предъявляли жалобы на боли в поясничном отделе позвоночника, иррадиирующие в одну или обе нижние конечности, усиливающиеся при движении и нарушающие сон. По данным визуальной аналоговой шкалы средний показатель боли составил $6,4 \pm 0,3 \mathrm{~cm}$ в 1-й группе больных и $6,2 \pm 0,1$ см во 2-й группе, что соответствует сильным по интенсивности болям.

Наряду с этим выявлялись болезненность паравертебральных точек (у 93 больных), напряжение мышц (у 62) и ограничение движений в поясничном отделе позвоночника (у 51). Часто определялись симптомы натяжения (у 78), снижение или выпадение сухожильных и периостальных рефлексов (у 42 больных), чувствительные нарушения по корешковому типу (у 43). Неврологическим обследованием у 58 больного были установлены рефлекторные синдромы, у 47 больных выявлялись комрессионные синдромы в виде радикулопатий.

Оценка болевого синдрома с помощью болевого опросника Мак-Гилл показала, что до лечения наиболее часто больные характеризовали боль по сенсорной субшка- ле, как пронизывающую (78 больных), тягостную (62 больных). Несколько реже пациенты отмечали пульсирующий (54 больных), грызущий (49) обжигающий (38) и тупой (35) характер боли. Другие характеристики болевого синдрома выявлялись в меньших случаях. По аффективной субшкале пациенты характеризовали боль как утомительно-изнуряющую (85 больных) и ослабляюще-тошнотворную (75 больных) боль. При анализе среднего балла интенсивности боли практически все характеристики болевого синдрома имели высокий балл, определяющий боль от "умеренной" до "сильной". Максимальный уровень интенсивности боли отмечен у больных с корешковыми синдромами в виде грызущей (2,8 $\pm 0,4$ балла), разрывающей $(2,8 \pm 0,2$ балла), пульсирующей $(2,7 \pm 0,2$ балла) и утомительно-изнуряющей $(2,7 \pm 0,2$ балла) боли.

Наряду с этим, по каждой субшкале в отдельности и в сумме вычисляли индекс дескрипторов (количество выбранных исследуемым показателей) и индекс рангов (сумма баллов выбранных дескрипторов) (табл.1). До лечения общая сумма дескрипторов составила в среднем 9,2 $\pm 0,02$ в 1-й группе больных и 6,2 $\pm 0,1$ в 2-й группе, общее. число рангов - 17,6 $\pm 0,03$ и $13,4 \pm 0,3$ соответственно.

Оценка показателей жизнедеятельности больных с помощью "Освестровского опросника нарушения жизнедеятельности при боли в нижней части спины" свидетельствовала о существенном влиянии проявлений НПОП на повседневную активность больных. Сильная интенсивность болей затрудняла самообслуживание больных. Большинство из них нуждались в некоторой помощи, боль позволяла им поднимать только легкие предметы, проходить не более 0,4 км, сидеть или стоять не более 30 мин, совершать прогулки не более 60 мин. Отмечалось также частое нарушение сна из-за болей и определенное ограничение в общественной жизни пациентов. Индекс качества жизни (ИКЖ) больных, являющийся суммарным показате- 
лем жизнедеятельности больных составил $65,8 \pm 2,8$ балла в 1-й группе больных и

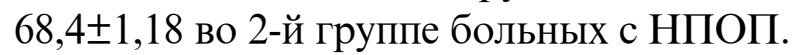

Электромиографическое исследование, проведенное в исходном состоянии, в состоянии покоя патологических изменений не выявило. При максимальном произвольном сокращении мышц регистрировались интерференционные электромиограммы со сниженной амплитудой биопотенциалов и уменьшением частоты осцилляторных колебаний в сравнении со здоровой стороной $(\mathrm{p}<0,01)$. При электронейромиографическом исследовании определялось снижение скорости проведения импульса по двигательным волокнам обследованных нервов, уменьшение амплитуды и площади М-ответа, удлинение длительности М-ответа (табл. 2). Следует отметить, что полученные изменения были наиболее выражены у больных с корешковыми синдромами, что очевидно обусловлено более грубым воздействием грыжи межпозвоночного диска на пораженные корешки.

Наблюдения за больными свидетельствовали о хорошей переносимости процедур в обеих группах больных. У больных 1-й группы после процедур криотерапии на месте воздействия наблюдалась бледность кожных покровов, сменяющаяся затем умеренной гиперемией, сопровождаемой чувством легкого жжения и онемения. Примененение нафталанотерапии через 2 часа после криовоздействия, способствовало устранению неприятных ощущений, снятию мышечного напряжения и общему расслаблению больных.

К концу курса лечения в обеих группах больных наблюдалось ослабление интенсивности болевого синдрома, мышечного напряжения, увеличение объема активных движений, выраженности симптомов натяжения и чувствительных расстройств.

Средняя интенсивность болей по ВАШ снизилась с $6,4 \pm 0,3$ см до 4,4 40,2 см в 1-й группе больных и с $6,2 \pm 0,1$ см до $3,9 \pm 0,2$ см во второй группе больных $(p<0,001)$. Коэффициент обезболивающего действия, высчитанный к концу курса лечения (табл.2) свидетельствовал об умеренном обезболивающем действии проводимого лечения в обеих группах.

Согласно данным болевого опросника Мак-Гилл, проведенное лечение способствовало уменьшению как интенсивности болевого синдрома, так и изменению характера боли. В обеих группах больных значительно уменьшилось количество пациентов, выбравших пронизывающую боль, пульсирующую и ослабляюще-тошнотворную Снижение интенсивности боли под влиянием проводимого лечения, а также уменьшение количества больных, предъявляющих жалобы на тот или иной характер боли, способствовали статистически достоверному уменьшению количественных параметров боли, определяемых по опроснику Мак-Гилл (табл. 2). Так, общий индекс дескрипторов снизился с 9,2 $\pm 0,02$ до 7,5 $\pm 0,04$ в 1-й группе боль-

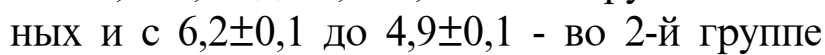

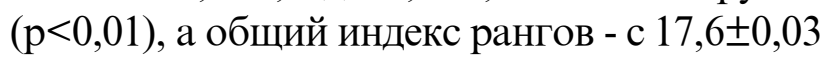

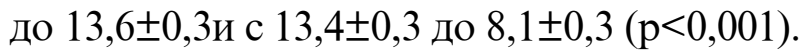

Положительная динамика основных клинических показателей у больных с НПОП отражалась и на качестве жизни больных. Под влиянием проводимого лечения отмечалось снижение интенсивности болей, улучшение самообслуживания, нормализация сна. С уменьшением болей улучшились походка, сидение и стояние больных, стало легче перемещаться. ИКЖ снизился в 1-й группе больных с 65,8 $\pm 0,02$ до 56,4 22,0 (p<0,01), a во 2-й группе больных с $68,4 \pm 1,18$ до $51,4 \pm 2,0$ $(\mathrm{p}<0,001)$. Сравнительный анализ показал, что улучшение КЖ отметили в $89 \%$ случаях после курса криотерапии и в 92\% случаях в группе больных, получавших криотерапию в комплексе с нафталанотерапией.

Общая оценка результатов лечения показала, что положительный терапевтический эффект в виде "значительного улучшения" и "улучшения" в 1-й группе больных с НПОП наблюдался у 44\% больных с корешковыми синдромами и 57\% больных с 
рефлекторными синдромами, а во 2-й группе - у 64\% и - 76\% больных соответственно.

Клиническое улучшение состояния больных в процессе проводимого лечения подтверждалось данными ЭМГ и ЭНМГ исследований. При повторном электромиографическом исследовании у больных обеих групп выявлялось увеличение амплитуды мышечных биопотенциалов и нарастание частоты осцилляторных колебаний в исследованных мышцах, однако отмеченные изменения были более выражены у больных 2-й группы ( $<<0,001)$.

Наряду с этим отмечалась положительная динамика электронейромиографических показателей, выражавшаяся в нарастании скорости проведения импульса по двигательным волокнам периферических нервов, увеличении амплитуды и площади М-ответа, укорочении его длительности (табл.2). Вместе с тем, сравнительный анализ динамики электронейромиографичеких показателей в обеих группах свидетельствовал о более значимых положительных изменениях у больных, получавших комплексное лечение..

Так скорость проведения импульса по малоберцовому нерву возросла у больных

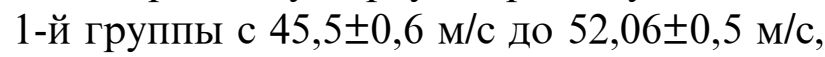
а во 2-й группе больных с 46,3 $\pm 0,5 \mathrm{~m} / \mathrm{c}$ до $51,8 \pm 0,5$ м/с , по большеберцовому нерву с $46,7 \pm 0,6$ м/с до $48,7 \pm 0,4 \mathrm{M} / \mathrm{c}(\mathrm{p}<0,01)$ - в 1-й группе и с $41,7 \pm 0,5 \mathrm{M} / \mathrm{c}$ до $51,8 \pm 0,5 \mathrm{~m} / \mathrm{c}$ $(\mathrm{p}<0,001)$ - во 2-й группе больных, что указывало на более выраженное улучшение проводящей функции периферических нервов под влиянием комплексного применения крио - и нафталанотерапии.

Таким образом, результаты проведен-

\section{ЛИТЕРАТУРА}

1. Белова А.Н. Шкалы, тесты и опросники в неврологии и нейрохирургии, М., 2004, 433 стр.

2. Абдулкина Н.Г., Алайцева С.В., Левицкий Е.Ф., Стрелис Л.П. Способ прогнозирования эффективности лечения неврологических проявлений поясничного остеохондроза позвоночника. www.ntpo.com.

3. Волотовская А.В., Колотович Г.К., Козловская Л.Е., Мумин А.Н. Криотерапия. Учебно-методическое пособие для врачей Минск, 2010. 22с. ных исследований показали, что применение криотерапии у больных с НПОП, как в виде монофактора, так и в комплексе с нафталанотерапией оказывает благоприятное влияние на клиническое течение заболевания, способствует уменьшению выраженности болевого синдрома, повышению качества жизни больных и улучшению функционального состояния периферического нейро-моторного аппарата.

Можно полагать, что положительный эффект криотерапии обусловлен ее противовоспалительным и спазмолитическим действием $[3,4]$, способствующим устранению отека, сдавления и защемления нервных корешков. В основе аналгезирующего действия криотерапии, вероятно, лежит блокада ноцицептивных рецепторов вследствие снижения температуры кожи, и как следствие, уменьшения поступления патологической болевой импульсации из периферии и дестабилизации формирующихся патологических альгических систем.

Применение нафталанотерапии во второй фазе криотерапии сопровождается более активным влиянием на функциональное состояние нервно-мышечного аппарата и оказывается наиболее эффективным у больных как с рефлекторными, так и с компрессионными синдромами остеохондроза позвоночника. Это свидетельствует о патогенетической направленности разработанной методики лечения, что по-видимому обусловлено взаимным потенцированием лечебного действия применяемых физических факторов, способствующим повышению эффективности проводимого лечения и нивелированию возможных побочных эффектов.

4. Гусарова С.А., Кузнецов О.Ф., Горбунов Ф.Е., Масловская С.Г. Методические аспекты применения криомассажа у больных, оперированных по поводу дискогенных нейропатий. Вопр. курортологии, физиотерапии и ЛФК, 2000, №4, с.20-22

5. Дембовский Д.О. Электронейромиография в диагностике и оценке эффективности лечения поясничного остеохондроза. Автореферат диссертации на соискание ученой степени к.м.н., М., 2008, 23c.

6. Зейналов Р.Г. Комплексное лечение больных с 
корешковыми синдромами поясничного остеохондроза с применением нафтеновых углеводородов нафталана в сочетании с ультрафиолетовыми лучами. Методические рекомендации, Баку, 1996, 9 с.

7. Кузнецов О.Ф. Криомассаж - Эффективная технология восстановительной терапии . Физиотерапия, бальнеология, реабилитация, 2003,№5, с.39-46. 8. Маркин С.П. Лечение больных с неврологическими проявлениями остеохондроза позвоночника. Вопр. курортологии, физиотерапии и ЛФК, 2005, №2, с.36-38
9. Мусаев А.В., Гусейнова С.Г., Мусаева И.Р. Постдискэктомический синдром: электронейромиографическая характеристика и методы лечения. Журнал неврологии и психиатрии. 2008, №1 с.23-30.

10. Попелянский Я.Ю. Болезни периферической нервной системы. М., 2005, 366с.

11. Рычаков Ю.В., Серая Э.В., Лапшин В.П. Криотерапия в острый период термоингаляционной травмы. Вопр. курортологии, физиотерапии и ЛФК, 2005, №4, с.33-38.

Таблица 1

Динамика болевого синдрома

\begin{tabular}{|l|l|l|l|l|}
\hline \multirow{2}{*}{ Показатели } & \multicolumn{2}{l|}{ До лечения } & \multicolumn{2}{l|}{ После лечения } \\
\cline { 2 - 5 } & 1 -я группа & 2 -я группа & 1 -я группа & 2 -я группа \\
\hline Индекс дескрипторов по сенсорной & $6,2 \pm 0,1$ & $4,1 \pm 0,1$ & $4,8 \pm 0,07 *$ & $3,4 \pm 0,08^{* *}$ \\
шкале по аффективной шкале & $3,0 \pm 0,2$ & $2,1 \pm 0,03$ & $2,7 \pm 0,02^{* *}$ & $1,2 \pm 0,03^{* *}$ \\
Общий бал & $9,2 \pm 0,02$ & $6,2 \pm 0,1$ & $6,5 \pm 0,04^{* *}$ & $4,9 \pm 0,1$ \\
\hline Индекс рангов по сенсорной шкале по & $10,7 \pm 0,2$ & $9,1 \pm 0,03$ & $6,3 \pm 0,02^{*}$ & $5,3 \pm 0,2^{* *}$ \\
аффективной шкале & $6,9 \pm 0,09$ & $4,4 \pm 0,1$ & $4,3 \pm 0,09 * *$ & $2,8 \pm 0,2^{* *}$ \\
Общий бал & $17,6 \pm 0,2$ & $13,4 \pm 0,3$ & $13,6 \pm 0,3 * *$ & $8,1 \pm 0,3$ \\
\hline ВАШ, см & $6,4 \pm 0,3$ & $6,2 \pm 0,1$ & $4,4 \pm 0,2^{* *}$ & $3,9 \pm 0,2^{* *}$ \\
КОд & & & & 0,31 \\
\hline
\end{tabular}

Примечание: р высчитан по отношению к исходному состоянию: * - p<0,01; ** - p<0,001

Таблица 2

\section{Динамика электронейромиографических показателей}

\begin{tabular}{|c|c|c|c|c|c|c|}
\hline \multicolumn{2}{|c|}{ Этапы лечения } & $\begin{array}{c}\text { Показатели } \\
\text { Нервы }\end{array}$ & $\begin{array}{c}\text { Амплитуда, } \\
\text { мВ }\end{array}$ & $\begin{array}{c}\text { Площадь, } \\
\text { мВ }\end{array}$ & $\begin{array}{c}\text { Длительност, } \\
\text { мс }\end{array}$ & $\begin{array}{c}\text { Скорость } \\
\text { м/c }\end{array}$ \\
\hline \multirow{2}{*}{ 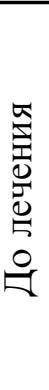 } & 1-я гр & $\begin{array}{l}\text { n.peroneus } \\
\text { n.tibialis }\end{array}$ & $\begin{array}{l}\frac{4,23 \pm 0,24}{6,38 \pm 0,22} \\
\frac{6,44 \pm 0,14}{8,63 \pm 0,22}\end{array}$ & $\begin{array}{l}\frac{15,2 \pm 0,12}{17,9 \pm 0,35} \\
\frac{14,9 \pm 0,9}{18,9 \pm 0,23}\end{array}$ & $\begin{array}{l}\frac{5,1 \pm 0,11}{4,3 \pm 0,11} \\
\frac{5,21 \pm 0,11}{4,9 \pm 0,08}\end{array}$ & $\begin{array}{l}\frac{43,4 \pm 0,6}{47,3 \pm 0,8} \\
\frac{44,1 \pm 0,4}{45,3 \pm 0,3}\end{array}$ \\
\hline & 2-я гр & $\begin{array}{l}\text { n.peroneus } \\
\text { n.tibialis }\end{array}$ & $\begin{array}{l}\frac{3,95 \pm 0,25}{5,97 \pm 0,18} \\
\frac{5,39 \pm 0,11}{8,95 \pm 0,19}\end{array}$ & $\begin{array}{l}\frac{14,8 \pm 0,11}{16,9 \pm 0,29} \\
\frac{15,2 \pm 0,13}{19,2 \pm 0,12}\end{array}$ & $\begin{array}{l}\frac{5,6 \pm 0,13}{4,7 \pm 0,12} \\
\frac{5,21 \pm 0,11}{5,3 \pm 0,09}\end{array}$ & $\begin{array}{l}\frac{42,2 \pm 0,5}{45,5 \pm 0,6} \\
\frac{41,7 \pm 0,5}{46,3 \pm 0,5}\end{array}$ \\
\hline \multirow{2}{*}{ 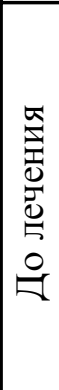 } & 1-я гр & $\begin{array}{l}\text { n.peroneus } \\
\text { n.tibialis }\end{array}$ & $\begin{array}{l}\frac{7,13 \pm 0,21 * * *}{10,3 \pm 0,42^{* * *}} \\
\frac{8,6 \pm 0,21 * *}{12,3 \pm 0,48 *}\end{array}$ & $\begin{array}{l}\frac{22,5 \pm 0,12^{* *}}{23,4 \pm 0,11^{* *}} \\
\frac{17,8 \pm 0,12^{* * *}}{21,2 \pm 0,11^{* * *}}\end{array}$ & $\begin{array}{l}\frac{4,28 \pm 0,12^{* * *}}{4,01 \pm 0,08^{* *}} \\
\frac{4,7 \pm 0,18^{* *}}{4,6 \pm 0,11^{*}}\end{array}$ & $\begin{array}{l}\frac{45,2 \pm 0,4^{* *}}{49,6 \pm 0,4^{* *}} \\
\frac{46,7 \pm 0,2^{* *}}{47,5 \pm 0,1^{* * *}}\end{array}$ \\
\hline & 2-я гр & $\begin{array}{l}\text { n.peroneus } \\
\text { n.tibialis }\end{array}$ & $\begin{array}{l}\frac{8,26 \pm 0,25^{* * *}}{12,8 \pm 0,51^{* * *}} \\
\frac{8,71 \pm 0,22^{* *}}{7,21 \pm 0,24 * * *}\end{array}$ & $\begin{array}{l}\frac{25,9 \pm 0,16^{* * *}}{27,1 \pm 0,12^{* * *}} \\
\frac{19,7 \pm 0,12^{* * *}}{23,5 \pm 0,15^{* * *}}\end{array}$ & $\begin{array}{l}\frac{3,95 \pm 0,11 * * *}{3,92 \pm 0,12 * * *} \\
\frac{4,01 \pm 0,15 * * *}{4,2 \pm 0,11 * *}\end{array}$ & $\begin{array}{l}\frac{48,8 \pm 0,4^{* * * *}}{52,6 \pm 0,5^{* * *}} \\
47,5 \pm 0,4^{* * *} \\
51,8 \pm 0,5^{* * *}\end{array}$ \\
\hline
\end{tabular}

Примечание: р высчитан по отношению к исходному состоянию * $-\mathbf{p}<0,02 ; *$ * p $<0,01$; *** - p<0,001; в числителе показатели с больной стороны, в знаменателе - с интактной 